\title{
Urban sprawl: can it be sustainable? An analysis on energy performances of different urban forms
}

\author{
C. Diamantini \& D. Vettorato \\ Department of Civil and Environmental Engineering, \\ University of Trento, Italy
}

\begin{abstract}
It is generally accepted that urban sprawl creates problems around energy use. It is true that the spread of single-family dwellings increases heat dispersion because of the bigger exterior surface of buildings. Moreover, families living far from city centres are reliant on their cars. Many urban planners are therefore calling for a stop to urban sprawl and a corresponding increase in urban compactness. In this paper we propose an alternative view. Alongside serious environmental issues in relation to energy, each urban form has the potential to fulfill the criteria of sustainability, particularly if such potential is exploited by means of planning practices. Our thesis is that the different forms assumed by settlements are not to be considered, in themselves, simply as strength or weakness factors but rather as variables. If these variables are adapted properly it is possible to have a significant impact on energy performance.

The analysis uses three parameters: energy saving and conservation, energy efficiency and renewable energy sources. It is assumed that we are dealing with a post-carbon era, in which all urban forms have the opportunity to maximize these parameters.
\end{abstract}

Keywords: urban sprawl, urban compactness, urban form, energy performances.

\section{Introduction}

Many scholars see urban sprawl as a distortion of the process of urbanization, which for centuries has been based on the model of the compact city. This negative view has been strengthened by the growing acceptance of the paradigm 
of sustainability [1], which has focused attention on, among other factors, the need to tackle climate change by limiting green house gas emissions. It is pointed out that urban sprawl contributes to an increase in emissions, both from fixed sources, domestic heating in particular, and from mobile ones, the overuse of the private car. Most scholars have therefore concluded that urban sprawl must be halted, with a return to compact urban areas $[2,3]$. We, however, have a different perspective on the question.

In modern market economies today the phenomenon of urban sprawl appears to be so intimately linked to the urbanization process as to be unstoppable. This is a result of economic advantages - like the low cost of land in areas considered desirable - which are hard to control through planning without potentially threatening individual freedoms. It is therefore not so much a question of stopping the unstoppable as of guiding the process with planning decisions, which are themselves based on the concept of sustainability. Though this might seem paradoxical, it need not be so.

Urban sprawl actually seems to be adapting itself to the recent trend towards the generation of renewable energy by numerous small and middle-sized installations; a feasible strategy for achieving a sustainable use of energy resources [4]. This small or medium sized energy production, at the level of the family home or the community, is more suitable for sparse settlements than for compact cities. Furthermore, changing urban microclimates, which lead to the creation of heat islands, are most common in compact cities, not in low-density areas or in zones where the urban and natural environments are well integrated [5]. Individual mobility, without question exacerbated by urban sprawl, is definitely a more critical factor. Even here, however, recent studies have shown that compact cities are also responsible for the generation of increased individual mobility: pushing their inhabitants to look outside them in search of pleasant environments and thus causing an increase in energy-expensive journeys [2]. Moreover, journeys to access services and commercial centers - often spread over wide areas - in turn stimulate traffic flows from compact cities which appear to be considerably greater than those undertaken for the same reasons within sparse settlements. These remarks, let it be said, are not aimed at a sort of replacement of compact cities with sparse settlements, by suggesting that the latter might, seen in perspective, reveal themselves to be more sustainable than the former.

We are, instead, of the opinion that the opposition between compact and sparse needs to be overcome, as we are convinced that all urban forms (understood as distinct parts of a settlement system) have the potential to fulfill sustainability criteria in relation to energy, particularly if such potential is exploited by means of planning choices. Our thesis is that the different forms assumed by settlement systems are not to be considered, in themselves, simply as strength or weakness factors, but rather as variables. If these variables are adapted properly, it is possible to have a significant impact on energy performance.

The paper thus aims to demonstrate the potential adaptability of different urban forms to the criteria of sustainable energy production and use, starting, 
according to some authors $[6,7]$, from the relationships which are established, both in compact cities and in low density areas, between urban morphologies understood as the structures making up urban form - and energy performance, with reference to three parameters of sustainability: energy saving and conservation, energy efficiency and renewable energy sources [8]. The choice of these three parameters implies operation in a sort of post-carbon dimension, in which all urban forms have the wherewithal to maximize their energy performance.

The energy performance of the different urban forms is investigated at the territorial scale - with reference to an Alpine city and its surrounding area - so uniting city and country in a single analytical context whose different urban forms are examined. The fact that the study is carried out at the territorial scale also gives us the opportunity to go further than the single building scale, which is the usual focus of energy studies.

Section 2 introduces the area of study, breaking it up into urban compactness profiles, from which the urban forms examined in the research are also obtained.

Section 3 presents our methods of analysis, with reference to both the indicators used and to the instruments with which they are described, focusing particularly on the most important indicators.

Section 4 presents our results, in the form of a comparison between the energy performances of the different urban forms, referring to the three parameters mentioned above.

The conclusions finally consider the significance of, and directions suggested by, the results of the study.

\section{Urban compactness profiles and urban forms}

The study area, fig. 1, extends from Trento (a city in an Alpine valley, pop. $100,000)$ to the Valsugana, a narrow valley that is undergoing urban sprawl. The settlement system under examination is characterized by the existence, a part from the city, of many small centers, of varying sizes, which have developed over time both through endogenous development and a process of suburbanization originating in the city.

In order to test the energy performances of the different urban forms, which make up the settlement structure of the area, different urban compactness profiles were first identified within it. This was done, following the Hill-Climbing method [9], through a cluster analysis, which used two variables that were also used for this purpose in the EEA [1]: population density and building density. The population density, measured in inhabitants per $\mathrm{km}^{2}$, was taken from the 2001 Census and then mapped using pixels with a $100 \mathrm{~m}$ resolution, while the building density, measured in $\mathrm{m}^{3} / \mathrm{m}^{2}$, was taken from a LiDAR survey and mapped using the same resolution. The cluster analysis gave us five urban compactness profiles which are related to an equal number of urban land uses in order to establish some spatial references, tab. 1. 


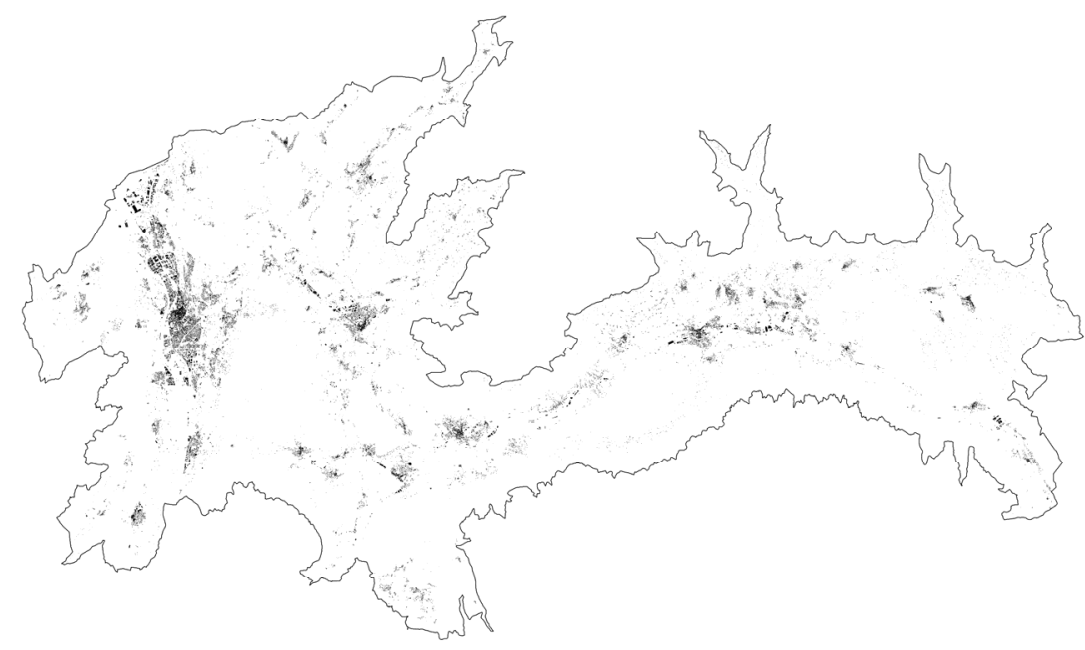

Figure 1: $\quad$ The study area.

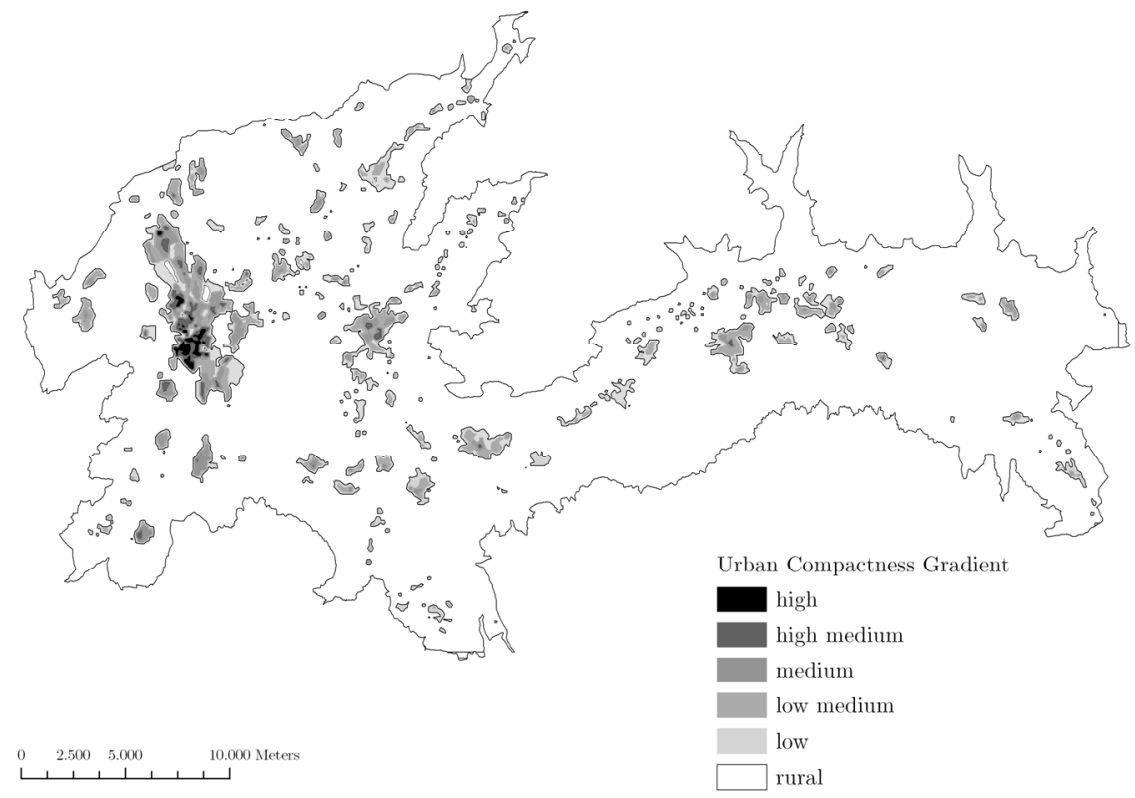

Figure 2: $\quad$ Urban compactness gradient map. 
The historical centers are the most compact forms (profile 1) - particularly the biggest, in the city of Trento - and, to a lesser extent (profile 2), in the historical centers of the small towns as well as in those parts of the territory affected by property development, particularly in the 1970s and 80s.

Profile 3, areas of medium urban compactness, corresponds mainly to the areas where big commercial centers and service infrastructure were built. The most common level of compactness, the low-medium (profile 4), is found in the areas which have undergone a process of suburbanization, which originates both in Trento and in the medium-sized towns of the valley. In Profile 4 we find the majority of the single-family dwellings. Profile 5, finally, covers both the ongoing suburbanization and pre-existent rural dwellings.

The five urban compactness profiles were then transferred into the Urban Compactness Gradient (UCG) map, fig. 2, from which the urban forms were obtained, through the spatial aggregation of adjacent areas.

Therefore, the urban forms emerge from the delimiting of the boundaries of the built-up areas, producing an image of an archipelago in which each island is an urban form, each of which contains different gradients of compactness. It is worth pointing out that these different gradients occur in different contexts; within the city as well as in the smaller centers. This indicates that, at least in the area under discussion, the equations city equal to compactness and countryside equal to sprawling are not strictly accurate since within the city perimeter there are low-density areas, while the countryside evidences some built areas with a high level of compactness.

Table 1: Compactness profiles and corresponding land uses.

\begin{tabular}{|l|l|l|}
\hline & Urban compactness profiles & Land uses \\
\hline 1 & high urban compactness & Historical centres \\
\hline 2 & high-medium urban compactness & First urban development \\
\hline 3 & medium urban compactness & Services and commercial areas \\
\hline 4 & low-medium urban compactness & Sub-urban development \\
\hline 5 & low urban compactness & Sparse settlements \\
\hline
\end{tabular}

\section{Energy performance indicators}

In order to select the spatial indicators we considered the interactions between urban morphologies and sustainable energy performance, referring to the three above mentioned parameters - energy saving and conversation, energy efficiency and renewable energy resources. There is considerable literature on the subject, but it is very fragmented, as authors have generally dealt with the specific aspects of the question $[4,5,10]$.

We selected 18 indicators from the available literature and these were turned into spatial metrics - according to the Pattern Oriented Modeling method - in order to use patterns, spatial in this case, to synthesize the complex interactions between urban morphology and sustainable energy. The list of spatial metrics, as matrix of interactions between urban morphology and the parameters of sustainable energy, is shown in figure 3. 
When the spatial metrics have been calculated they were normalized on a pixel grid of $100 \mathrm{~m}^{2}$ in order to, on the one hand, compare them and, on the other, to construct a ranking system in relation to the energy performance of the individual pixels. Figures 4 and 5 show two of the spatial metrics, here referred to the city area only, which we used in the study: the Incident Solar Radiation and the Floor to Area Ratio.

The study then looked at an additional variable, the UCG mentioned above, in order to establish the correlations between the variations in the spatial metrics and therefore of the sustainable energy performances - and the different degrees of urban compactness. These correlations - bearing in mind that each pixel stands for 18 metrics plus the UCG - were subject to a multivariate statistical analysis.

\begin{tabular}{|c|c|c|c|}
\hline Saving and Conservation & Efficiency & Renewable Sources & Spatial Metrics \\
\hline Local climate conditions & & & Climate zones \\
\hline $\begin{array}{l}\text { Natural sun exposition / } \\
\text { lighting }\end{array}$ & & & Available bours of light $/ \mathrm{m} 2 /$ day \\
\hline \multirow[t]{4}{*}{ Road network slope } & & & Land slope in degrees \\
\hline & $\begin{array}{l}\text { Main road network } \\
\text { density }\end{array}$ & & Spatial density of main road network \\
\hline & & Solarpower potential of land & $\begin{array}{l}\text { Incident sun beam irradiation in } \\
\mathrm{W} / \mathrm{m} 2 / \text { day }\end{array}$ \\
\hline & & Biomasspower potential of land & Biomass availability in $\mathrm{m} 3 / \mathrm{ha} /$ year \\
\hline \multirow[t]{2}{*}{ Urban Heat Island aptitude } & & & Overheating aptitude of surfaces \\
\hline & \begin{tabular}{|l} 
Building thermal \\
conservation
\end{tabular} & & Building compactness \\
\hline $\begin{array}{l}\text { Housing and urban services } \\
\text { proximity }\end{array}$ & & & Spatial density of urban services \\
\hline \multirow[t]{3}{*}{ Housing and job proximity } & & & Job density \\
\hline & $\begin{array}{l}\text { Secondary road } \\
\text { network density }\end{array}$ & & $\begin{array}{l}\text { Spatial density of secondary road } \\
\text { network }\end{array}$ \\
\hline & $\begin{array}{l}\text { Public transport } \\
\text { accessibility }\end{array}$ & & Public transport stops density \\
\hline \multirow[t]{2}{*}{$\begin{array}{l}\text { District Heating and } \\
\text { Cooling suitability }\end{array}$} & & & Floor to area ratio (FAR) \\
\hline & & $\begin{array}{l}\text { Ground source heat pump } \\
\text { (GSHP) potential }\end{array}$ & GSHP suitability \\
\hline $\begin{array}{l}\text { Natural illumination of } \\
\text { buildings }\end{array}$ & & & $\begin{array}{l}\text { Avaliable } \mathrm{h} / \text { light } / \mathrm{m} 2 \text { on building } \\
\text { surface }\end{array}$ \\
\hline \multirow[t]{3}{*}{ Green area factor } & & & $\begin{array}{l}\text { Normalized Difference Vegetation } \\
\text { Index (NDVI) }\end{array}$ \\
\hline & $\begin{array}{l}\text { Walkability and } \\
\text { bikeability }\end{array}$ & & $\begin{array}{l}\text { Spatial density of tertiary road } \\
\text { network }\end{array}$ \\
\hline & & $\begin{array}{l}\text { Photovoltaic and thermal } \\
\text { potential energy of roofs and } \\
\text { facades }\end{array}$ & $\begin{array}{l}\text { Incident sun beam irradiation on } \\
\text { buildings surfaces (roofs and } \\
\text { facades) in } w / m 2 / \text { day }\end{array}$ \\
\hline
\end{tabular}

Figure 3: $\quad$ Spatial metrics.

\section{Outcomes and results}

The effectiveness of this study method is clearly shown by the outcomes obtained through the multivariate analysis. In figure 6 , in fact, appear significant correlations - through a grey-scale - between the spatial metrics used as variables and the UCG. 


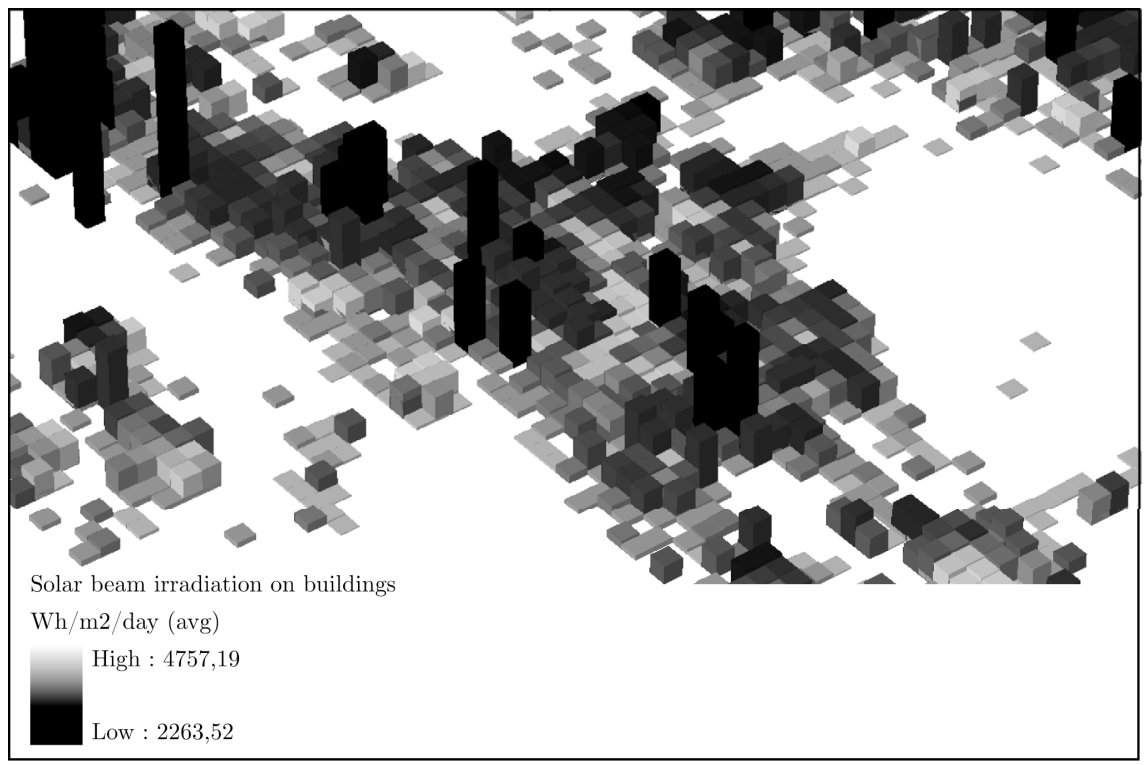

Figure 4: $\quad$ Incident solar radiation.

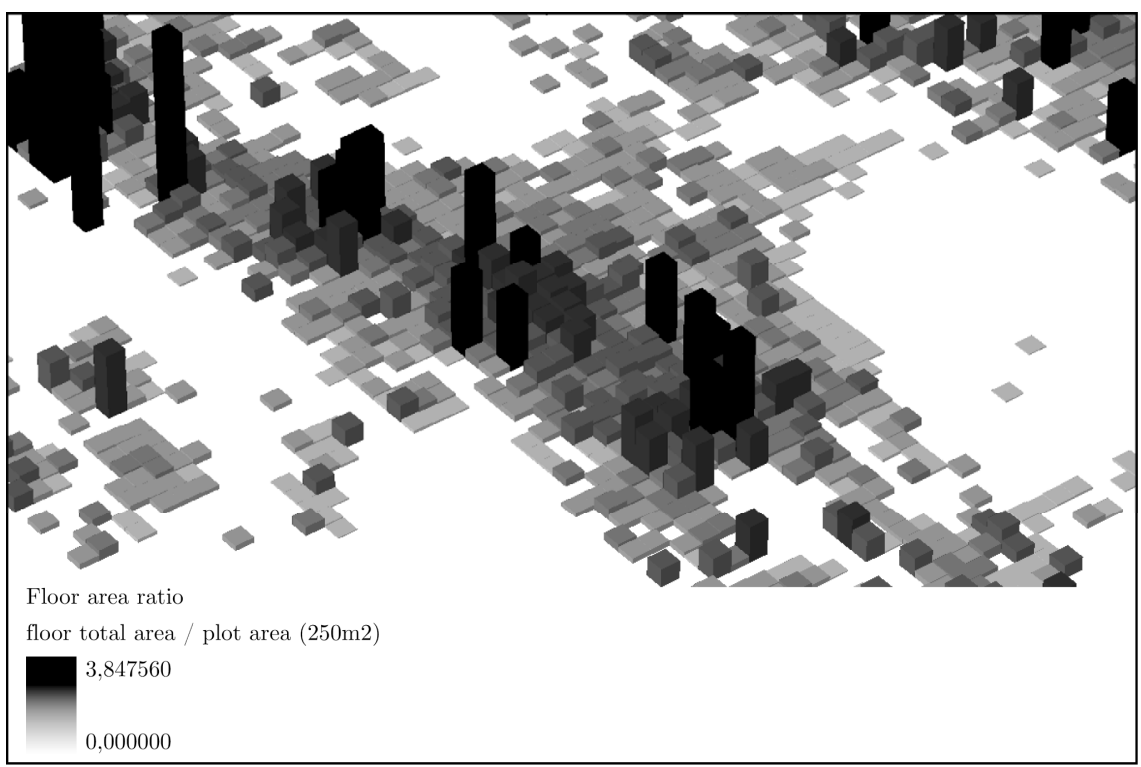

Figure 5: $\quad$ Floor to area ratio. 


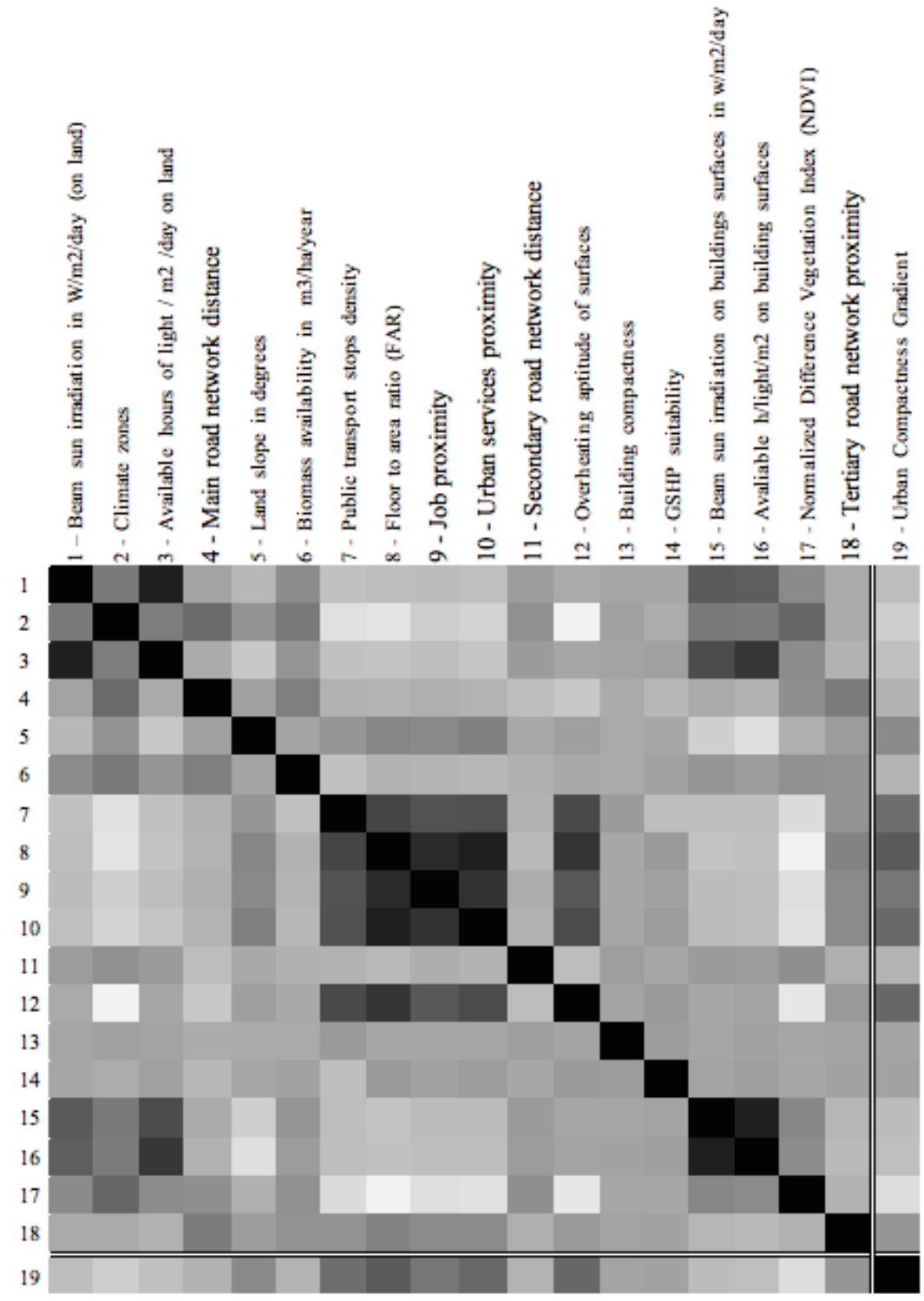

High positive correlation

\section{Low correlation}

High negative correlation

Figure 6: Correlations between the spatial metrics used and the UCG. 
If we look at two profiles of urban compactness - the most compact (profile 1) and the least (profile 5) - which correspond to the most compact areas of the city and to the sparsest settlements, we see that the former seems to be closely correlated with one of the parameters used for the analysis - energy saving and conservation - and much less with the other two, while the second seems to be closely correlated with another of these parameters, renewable energy sources.

Another important outcome, although it is determined by the characteristics of this particular area, arises from the important multi-scale relationship, which we find between the patterns of energy performance. The level of exposure of exterior building surfaces to beam solar radiation, for example, is firstly a product of the location of a settlement within the region, and secondly of the urban structure.

Lastly, a ranking system, using thresholds and scores, allows us to see the sustainable energy performance of the urban forms, giving them the scores of the corresponding pixels. Table 2 shows a sample of thresholds and scores, taken from the literature on the subject $[10,11]$. They can be improved turning to a participatory approach.

Table 2: $\quad$ Sample of thresholds and scores.

\begin{tabular}{|l|c|c|c|}
\hline 1. Beam sun & High (3 points) & $\begin{array}{c}\text { Medium } \\
(2 \text { points })\end{array}$ & Low (1 point) \\
\hline $\begin{array}{l}4000 \\
\mathrm{wh} / \mathrm{m}^{2} / \text { day }\end{array}$ & $\begin{array}{c}2500-4000 \\
\mathrm{wh} / \mathrm{m}^{2} / \text { day }\end{array}$ & $\begin{array}{c}<2500 \\
\mathrm{wh} / \mathrm{m}^{2} / \text { day }\end{array}$ \\
\hline 2. Climate zone & Zone 1 & Zone 2 & Zones 3 and 4 \\
\hline $\begin{array}{l}\text { 3. Hours of light } \\
\text { 4. Main roads } \\
\text { distance }\end{array}$ & $500 \mathrm{~m}-1000 \mathrm{~m}$ & $1000 \mathrm{~m}-2000 \mathrm{~m}$ & $\begin{array}{c}<500 \mathrm{~m}, \\
>2000 \mathrm{~m}\end{array}$ \\
\hline $\begin{array}{l}\text { 5. Land slopes } \\
\text { (degrees) }\end{array}$ & $<10^{\circ}$ & $10^{\circ}-15^{\circ}$ & $>15^{\circ}$ \\
\hline $\begin{array}{l}\text { 6. Biomass } \\
\text { availability }\end{array}$ & $>10 \mathrm{~m} / \mathrm{h} / \mathrm{hay} / \mathrm{year}$ & $5-10 \mathrm{~m}^{3} / \mathrm{ha} / \mathrm{year}$ & $<5 \mathrm{~m}^{3} / \mathrm{ha} / \mathrm{year}$ \\
\hline
\end{tabular}

Three performance maps have thus been created, referring to the three parameters of energy sustainability used in the analysis. These maps, as shown in figures 7, 8 and 9, allow us to make comparisons between the sustainable energy performances of the different urban forms. 


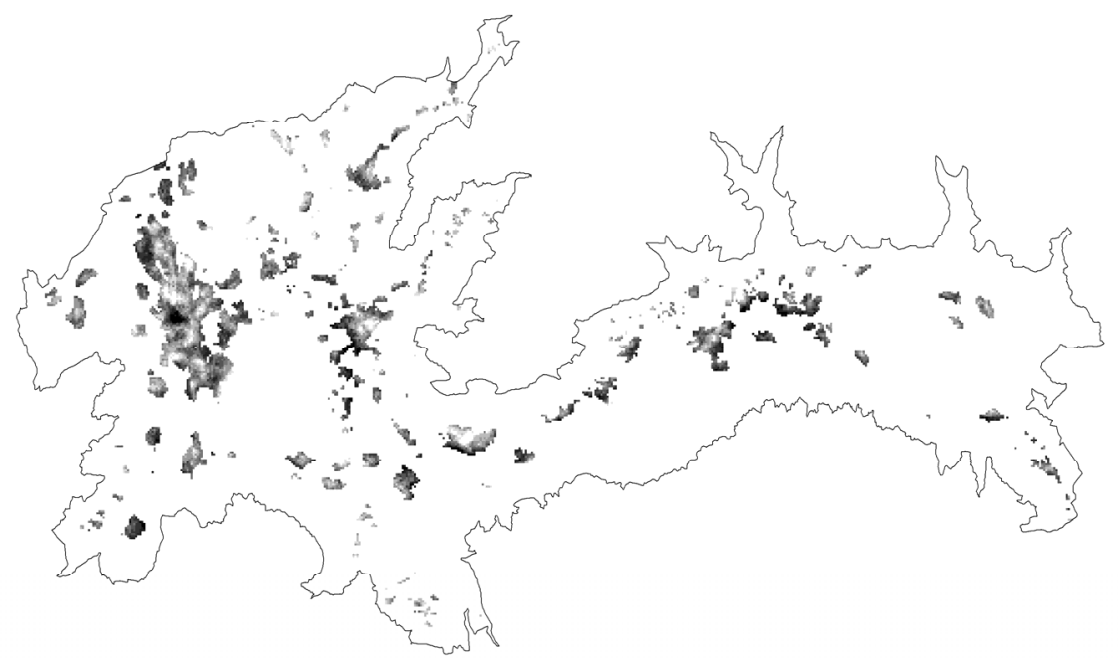

Saving and Conservation

High : 27

\begin{tabular}{l}
$0 \quad 2.500 \quad 5.000 \quad 10.000$ Meters \\
\hline
\end{tabular}

Low : 14

Figure 7: $\quad$ Energy saving and conservation.

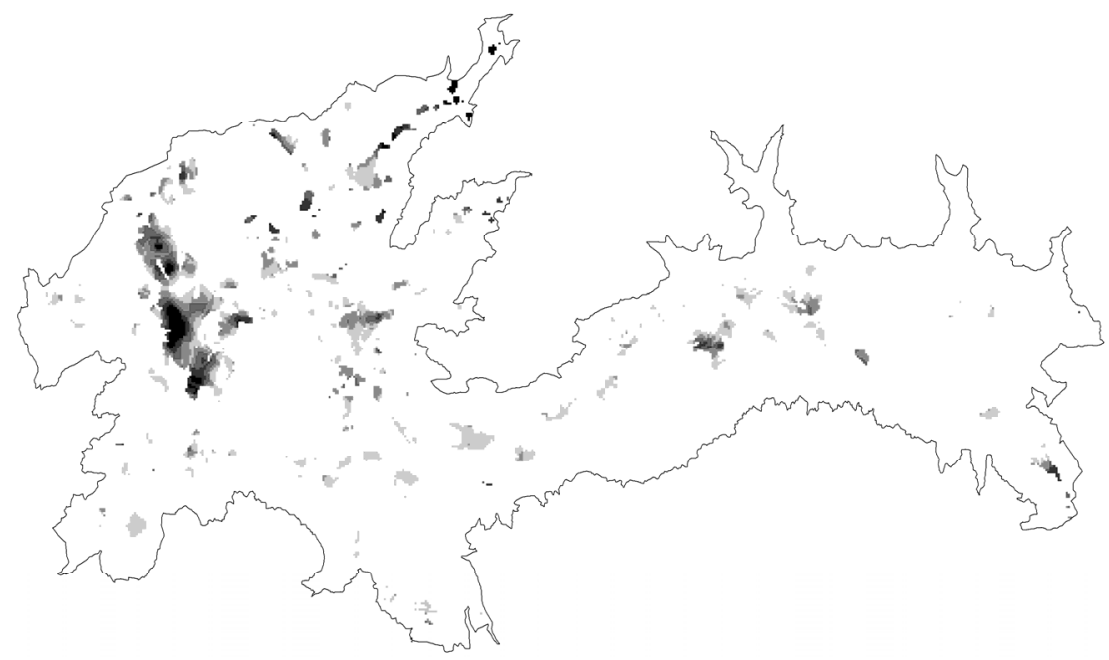

Efficiency

High : 13

Figure 8: $\quad$ Energy efficiency. 


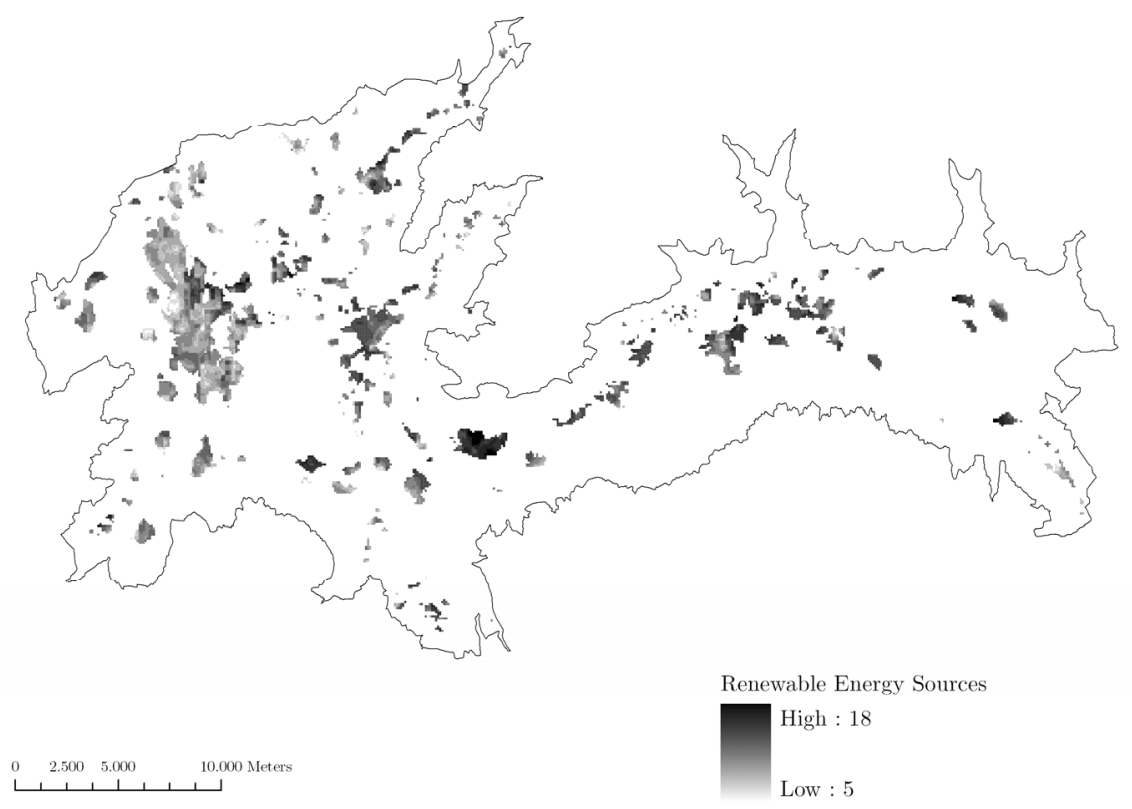

Figure 9: $\quad$ Renewable energy sources.

When we look at the energy saving and conservation criteria the form of a settlement does not seem to affect energy performance; there is no significant difference between the city and the small towns. Energy efficiency, however, seems to be highest in the city, while the small towns are at a disadvantage. From the point of view of renewable energy resources the small centers seem to perform best and it is the city's turn to be handicapped.

\section{Conclusions}

The initial assumption of this paper was that, considered from the perspective of sustainable development, the opposition between the compact city and the diffuse city is losing its validity. This is because very soon all type of settlement will have to adapt to criteria of sustainability like energy saving and conservation, energy efficiency and renewable energy sources.

It is therefore a question, without setting them up in opposition to each other a priori, of verifying the ability of the different urban forms to adapt to these criteria and, if necessary, to take action, through planning practices, in order to create the conditions of such an adaptation. In order to demonstrate this we have used the criteria of sustainable use of energy resources referred to above to compare the energy performance of different urban forms.

The following conclusions may be drawn from our analysis: 
Our methodology proved to be effective in describing the sustainable energy performance of urban forms through both morphology and compactness gradient.

The hypothesis that urban compactness is not the only approach to be used in planning practices to achieve high levels of sustainable use of energy resources is confirmed by the empirical observations presented in our study. We see, in particular, that although compact cities are more energy efficient, less densely built areas are more suitable for renewable energy generation.

The analysis of energy performance from a morphological point of view allows us to identify critical of intervention in order to bring them into line with sustainability criteria.

The lack of data and the ad hoc methods used for our spatial analysis has forced us to make some approximations. It was not possible to use a single unit of measurement for the spatial patterns of energy performance. This means that the results have been subject predominantly to visual comparisons. Likewise, it isn't possible to compare performance data from other studies conducted using different methodologies. Future developments should identify a unit of quantitative measurement of energy performance and the necessary conversion formulae to be used in the research works.

\section{References}

[1] European Environmental Agency, Urban sprawl in Europe. The ignored challenge, Report 10, EEA: Copenhagen, 2006.

[2] Jenks, M., Burton, E. \& Williams K., The Compact City: A Sustainable Urban Form? Oxford University Press: Oxford, 1996.

[3] O’Mehara Sheenan, M., City Limits: Putting the Brakes on Sprawl, Worldwatch Paper 156, Worldwatch Institute: Washington DC, 2001.

[4] International Energy Agency-Organization for Economic Co-operation and Development, City, town and Renewable Energy. Yes In my Front Yard, IEA/OECD: Paris, 2009.

[5] Gartland, L., Heat islands: understanding and mitigating heat in urban areas, Earthscan: London, 2008.

[6] Owens, S.E., Energy, Planning and Urban Form, Pion: London, 1986.

[7] Alberti, M., Advances in Urban Ecology. Integrating Humans and Ecological Processes in Urban Ecosystems, Springer: Washington, 2008.

[8] European Commission, Intelligent Energy Europe. Mapping of previous integrated energy approaches, Part 2, EU INTEND project, task 2.1, EIE06-021-INTEND, EU: Bruxelles, 2005.

[9] Rubin, J., Optimal Classification into Groups: An Approach for Solving the Taxonomy Problem, J. Theoretical Biology, 15, pp. 103-144, 1967.

[10] U.S. Green Building Council, LEED Reference Guide for Neighborhood Development. 2009 Edition. USGBC: Washington D.C., 2009.

[11] Hanova, J., Dowlatabadi, H., Strategic GHG reduction through the use of ground source heat pump technology, Environmental Research Letters, 2 (4), pp. 1-8, 2007. 